\title{
An Availability Model for the SNS Linac RF System*
}

\author{
Paul Tallerico, Daniel Rees, David Anderson ${ }^{\dagger}$ \\ Los Alamos National Laboratory, Los Alamos, NM 87545 USA \\ ${ }^{\dagger}$ Oak Ridge National Laboratory, Oak Ridge, TN 37830 US
}

\section{Abstract}

The Linac RF system is broken down into eight major components for this model. These components are: the klystrons, the waveguide, the water loads, the circulators, the converter/modulator, the transmitter, the window, and the low level RF (LLRF) controls. The mean time between failures (MTBF) for several of the components vary with voltage or klystron power level, and this variation is discussed below. In general, these MTBF's are design requirements supplied to the vendors of the subsystems, and verified at design reviews and by the experience at other accelerators. We assume that the scheduled operational time for the SNS is 6000 hours per year, and use this number to calculate the availability. We have to calculate the total down time during the 6000 hours of operation, and the availability is defined as one minus the unexpected down time for the year, divided by the number of operating hours in the year. Ideally, we would use distributions of MTBF's and MTTR's, since each failure will be different, but the equipment is not yet built, so the distributions are not available, and we make the assumption of constant MTBF and MTTR.

\section{INTRODUCTION}

The RF system for the SNS linac is described in a companion paper. The availability is calculated by summing the down times of the components of the RF system, and the using the total down time in the availability relation. The down time is the number of failures in the year of operation times the mean time to

\begin{tabular}{|l|l|l|l|l|}
\hline System & $\begin{array}{l}\text { RFQ } \\
\text { DTL }\end{array}$ & $\begin{array}{l}\text { NC } \\
\text { CCL }\end{array}$ & SRF & HEBT \\
\hline Frequency & 402.5 & 805 & 805 & 805 \\
& $\mathrm{MHz}$ & $\mathrm{MHz}$ & $\mathrm{MHz}$ & $\mathrm{MHz}$ \\
\hline Klystron & $7 @ 2.5$ & $4 @ 5$ & $81 @$ & $\mathbf{2} @$ \\
& $\mathrm{MW}$ & $\mathrm{MW}$ & $550 \mathrm{~kW}$ & $5 \mathrm{MW}$ \\
\hline Transmitter & $7 @$ & $4 @ 135$ & $14 @$ & $2 @ 97$ \\
& $118 \mathrm{kV}$ & $\mathrm{kV}$ & $75 \mathrm{kV}$ & $\mathrm{kV}$ \\
\hline Converter & $3 @$ & $4 @ @$ & $7 @$ & $1 @$ \\
Modulator & $105 \mathrm{~A}$ & $64 \mathrm{~A}$ & $136 \mathrm{~A}$ & $87 \mathrm{~A}$ \\
\hline Waveguide & $7 @ 2$ & $4 @$ & $81 @$ & $2 @$ \\
& $\mathrm{MW}$ & $4 \mathrm{MW}$ & $410 \mathrm{~kW}$ & $2 \mathrm{MW}$ \\
\hline Windows & $6+8$ & $\mathbf{8} @$ & $81 @ 9$ & $2 @$ \\
& small & $2 \mathrm{MW}$ & $410 \mathrm{~kW}$ & $2 \mathrm{MW}$ \\
\hline
\end{tabular}

Table 1. Summary of the RF system of the SNS linac.

repair or replace, denoted here as MTTR, in hours.

* Work supported by the Office of Basic Energy Science, Office of Science of the US Department, and by Oak Ridge National Laboratory
Note that the mean time to repair is important, since it determines how much manpower will be used in the repair process and how many spares have to be stocked. We assume here that the spare parts storage is complete enough that we can replace any unit at will, when required. We assume that the linac is regularly subjected to scheduled maintenance, typically (at LANSCE) one 4 or 8 hour shift per week. Repairs made during this maintenance period do not count as down time. The linac is a series connection of several accelerator components, and the RF system is best understood by studying Table 1 , which shows the various major components of the linac $\mathrm{RF}$ system. In the table, NC and SRF stand for normal conducting and super conducting, as this linac has both types of coupled cavity accelerator sections.

In this RF system, the transmitter includes the cooling system, the power distribution system, and measurement system for the klystron and for the accelerator window. The transmitter is thus large and distributed, its MTBF is required in our specifications to be greater than 8000 hours. Although the MTTR specification goal for the transmitter is 1 hour, we use a 2 hour MTTR, since safety procedures and fault location have to be done before the repair or replacement work can start. A 3 hour MTTR is used for the larger transmitters in the superconducting sections. This is not inconsistent with our experience with similar transmitters for LEDA. The MTBF for the klystrons, loads, and circulators come from their specifications. The MTBF was calculated from the components for the converter modulator and the transmitters. The mean time to repair these components was estimated from the times that similar replacements or repairs take place at the LANSCE or other appropriate accelerator complexes. The MTTR of the windows is estimated as 12 hours in the normal conducting sections, and 24 hours in the superconducting sections.

\section{$2 \quad 402.5$ MHZ RF SYSTEM}

The RFQ and DTL RF systems are lumped together, since their power levels and operating frequency are the same. The RFQ has eight low power windows, while each DTL has a single $2 \mathrm{MW}$ window, and this important difference will be accounted for below. There is one klystron for the RFQ, and six klystrons for the DTL. All klystrons have a circulator, and a load on the circulator. The klystrons are rated at $2.5 \mathrm{MW}$ peak output power at $9 \%$ duty factor, but they deliver $2.0 \mathrm{MW}$ peak power at $8 \%$ duty factor. Three converter/modulators and seven transmitters are used for these seven klystrons, since the RFQ and the first few tanks of the DTL require less power. All windows have a 100,000 hour MTBF, as required in our specifications. Each klystron has a LLRF 
system. The unscheduled down time per year for the 402.5 MH RF system is 32.4 hours, and it is calculated by Table 2 below.

\begin{tabular}{|c|c|c|c|c|c|}
\hline Component & 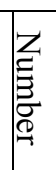 & $\begin{array}{l}\text { MTBF, } \\
\text { khr }\end{array}$ & $\begin{array}{l}\text { Failures } \\
\text { year }\end{array}$ & $\begin{array}{l}\text { MTTR, } \\
\mathrm{hr}\end{array}$ & $\begin{array}{l}\text { Down } \\
\text { Time/ } \\
\text { year, } \\
\text { hr }\end{array}$ \\
\hline Klystron & 7 & 50 & 0.84 & 3.0 & 2.52 \\
\hline $\begin{array}{l}\text { Wave } \\
\text { Guide }\end{array}$ & 7 & 150 & 0.28 & 4.0 & 1.12 \\
\hline Load & 7 & 75 & 0.56 & 3.0 & 1.68 \\
\hline Circulator & 7 & 50 & 0.84 & 3.0 & 2.52 \\
\hline $\begin{array}{l}\text { Converter/ } \\
\text { Modulator }\end{array}$ & 3 & 22.6 & 0.80 & 4.0 & 3.19 \\
\hline Transmitter & 7 & 8 & 5.25 & 2.0 & 10.5 \\
\hline $\begin{array}{l}\text { DTL } \\
\text { Window }\end{array}$ & 6 & 100 & 0.36 & 12.0 & 4.32 \\
\hline $\begin{array}{l}\text { RFQ } \\
\text { Window }\end{array}$ & 8 & 100 & 0.48 & 12.0 & 5.76 \\
\hline LLRF & 7 & 100 & 0.42 & 2.0 & 0.84 \\
\hline Totals & & & 9.83 & & 32.4 \\
\hline
\end{tabular}

Table 2. Down time allocation for the $402.5 \mathrm{MHz} \mathrm{RF}$ System.

\section{CCL RF SYSTEM}

The normal conducting section of the CCL RF system uses four $5 \mathrm{MW}, 805 \mathrm{MHz}$ klystrons, and the outputs are split once with a 3-dB hybrid. There are four circulators, four circulator loads, and four splitter loads.

\begin{tabular}{|c|c|c|c|c|c|}
\hline Component &  & $\begin{array}{l}\text { MTBF, } \\
\text { khr }\end{array}$ & $\begin{array}{l}\text { Failures } \\
\text { year }\end{array}$ & $\begin{array}{l}\text { MTTR, } \\
\mathrm{hr}\end{array}$ & $\begin{array}{l}\text { Down } \\
\text { Time/ } \\
\text { Year, } \\
\mathrm{hr}\end{array}$ \\
\hline Klystron & 4 & 50 & 0.48 & 3.5 & 1.68 \\
\hline $\begin{array}{l}\text { Wave } \\
\text { Guide }\end{array}$ & 8 & 150 & 0.32 & 3.0 & 0.96 \\
\hline Load & 8 & 75 & 0.64 & 3.0 & 1.92 \\
\hline Circulator & 4 & 50 & 0.48 & 3.0 & 1.44 \\
\hline $\begin{array}{l}\text { Converter/ } \\
\text { Modulator }\end{array}$ & 4 & 22.6 & 1.06 & 4.0 & 4.25 \\
\hline Transmitter & 4 & 8 & 3.00 & 2.0 & 6.0 \\
\hline Window & 8 & 100 & 0.48 & 12.0 & 5.76 \\
\hline LLRF & 4 & 100 & 0.24 & 2.0 & 0.48 \\
\hline Totals & & & 6.70 & & 22.5 \\
\hline
\end{tabular}

Table 3. Down time allocation for the $805 \mathrm{MHz}$, Normal Conducting CCL RF System.

Although the klystrons have twice the peak and average power as the $402.5 \mathrm{MHz}$ ones, the specification for the life estimate remains at 50,000 hours. All the
MTBF's and MTTR's are the same as for the $402.5 \mathrm{MHz}$ RF system, except for the MTTR of the klystron and the waveguide. Considering the larger size of the klystron and the need for more X-ray shielding, the MTTR (replace is this case) for the klystron is increased to 3.5 hours from 3 hours. The larger waveguide for the low frequency section will take longer to replace. The down times for the normal conducting CCL RF system sum up to 22 hours per year, and the details of this calculation are shown in Table 3.

The majority of the RF systems are the $81 \mathrm{RF}$ systems that drive the superconducting CCL system. The klystron have a $550 \mathrm{~kW}$ peak power rating, and each transmitter drives either five or six of these klystrons. Each converter modulator drives two transmitters, either eleven or twelve klystrons. The MTTR of the klystrons and the transmitters are increased to 4.5 and 3 hours, respectively. A summary of the down time calculations is shown in Table 4. Since the window change now involves superconducting cavity warm-up and cool-down, the window repair time is doubled to 24 hours. The vendor for the circulator has contracted for a 50,000 life expectancy for this lower power application. The total downtime per year for the superconducting CCL RF system is 280.9 hours, when we assume that the RF system must be repaired after each failure.

\begin{tabular}{|l|l|l|l|l|l|}
\hline Component & $\begin{array}{l}\text { 杰 } \\
\underset{\Xi}{\Phi}\end{array}$ & $\begin{array}{l}\text { MTBF, } \\
\text { khr }\end{array}$ & $\begin{array}{l}\text { Failures } \\
\text { year }\end{array}$ & $\begin{array}{l}\text { MTTR, } \\
\text { hr }\end{array}$ & $\begin{array}{l}\text { Down } \\
\text { Time/ } \\
\text { year, } \\
\text { hr }\end{array}$ \\
\hline Klystron & 81 & 50 & 9.72 & 4.5 & 43.7 \\
\hline $\begin{array}{l}\text { Wave } \\
\text { Guide }\end{array}$ & 81 & 150 & 3.24 & 3.0 & 9.72 \\
\hline Load & 81 & 75 & 6.48 & 3.0 & 19.4 \\
\hline Circulator & 81 & 50 & 9.72 & 3.0 & 29.2 \\
\hline $\begin{array}{l}\text { Converter/ } \\
\text { Modulator }\end{array}$ & 7 & 22.6 & 1.86 & 4.0 & 7.43 \\
\hline Transmitter & 14 & 5.6 & 15 & 3.0 & 45.0 \\
\hline Window & 81 & 100 & 4.68 & 24.0 & 116.6 \\
\hline LLRF & 81 & 100 & 4.68 & 2.0 & 9.73 \\
\hline Totals & & & 55.7 & & 280.8 \\
\hline
\end{tabular}

Table 4. Down time allocation for the $805 \mathrm{MHz}$, Super Conducting (SRF) RF System.

The last RF system is for the High Energy Beam Transport line, the HEBT. This section only has two RF cavities, two klystrons, and two transmitters. These 805 MHz klystrons are of the 5-MW type, but they are only operated at the $2 \mathrm{MW}$ level, so their life should increase. The total RF system down time is 8.0 hours and is calculated as in Table 5 . 


\begin{tabular}{|c|c|c|c|c|c|}
\hline Component &  & $\begin{array}{l}\text { MTBF, } \\
\text { khr }\end{array}$ & $\begin{array}{l}\text { Failures } \\
\text { year }\end{array}$ & $\begin{array}{l}\text { MTTR, } \\
\mathrm{hr}\end{array}$ & $\begin{array}{l}\text { Down } \\
\text { Time/ } \\
\text { year, } \\
\text { hr }\end{array}$ \\
\hline Klystron & 2 & 50 & 0.24 & 3.5 & 0.84 \\
\hline $\begin{array}{l}\text { Wave } \\
\text { Guide }\end{array}$ & 2 & 150 & 0.08 & 3.0 & 0.24 \\
\hline Load & 2 & 75 & 0.16 & 3.0 & 0.48 \\
\hline Circulator & 2 & 50 & 0.24 & 3.0 & 0.72 \\
\hline $\begin{array}{l}\text { Converter/ } \\
\text { Modulator }\end{array}$ & 1 & 22.6 & 0.27 & 4.0 & 1.06 \\
\hline Transmitter & 2 & 8 & 1.5 & 2.0 & 3.0 \\
\hline Window & 2 & 100 & 0.12 & 12.0 & 1.44 \\
\hline LLRF & 2 & 100 & 0.12 & 2.0 & 0.24 \\
\hline Totals & & & 2.73 & & 8.02 \\
\hline
\end{tabular}

\begin{tabular}{|c|c|c|c|c|c|}
\hline Component & 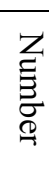 & $\begin{array}{l}\text { MTBF, } \\
\text { Khr }\end{array}$ & $\begin{array}{l}\text { Failures } \\
\text { Year }\end{array}$ & $\begin{array}{l}\text { MTTR, } \\
\mathrm{hr}\end{array}$ & $\begin{array}{l}\text { Down } \\
\text { Time/ } \\
\text { year, } \\
\text { hr }\end{array}$ \\
\hline Klystron & 81 & 50 & 9.72 & 2.25 & 21.9 \\
\hline $\begin{array}{l}\text { Wave } \\
\text { Guide }\end{array}$ & 81 & 150 & 3.24 & 0.25 & 0.81 \\
\hline Load & 81 & 75 & 6.48 & 0.25 & 1.62 \\
\hline Circulator & 81 & 50 & 9.72 & 0.25 & 2.43 \\
\hline $\begin{array}{l}\text { Converter/ } \\
\text { Modulator }\end{array}$ & 7 & 22.6 & 1.86 & 4.0 & 7.43 \\
\hline Transmitter & 14 & 5.6 & 15 & 3.0 & 45.0 \\
\hline Window & 81 & 100 & 4.86 & 24 & 116.6 \\
\hline LLRF & 81 & 100 & 4.86 & 0.25 & 1.22 \\
\hline Totals & & & 55.7 & & 197.0 \\
\hline
\end{tabular}

Table 5. Down time allocation for the $805 \mathrm{MHz}, \mathrm{HEBT}$ RF System.

\section{RESULTS AND REDUNDANCY IN THE SC CCL}

To arrive at the total RF system availability, we sum the unscheduled down times from the four major RF subsystems, and get 343.8 hours per year. This corresponds to an availability of $94.27 \%$, which is good for such a large linac, but unacceptable for the SNS. The availability can be improved because the super conducting linac design is likely to be tolerant of several types of single point failures, provided that the neighboring (or all the remaining higher energy) accelerating cavities are rephased to account for the energy not gained in the inoperative cavities. The super conducting linac may be designed to operate at lower energy (or lower current) even when a cavity, klystron, waveguide, circulator, load, low-level RF system, or window has failed. To do this we have to retune linac tanks (the array of coupled cavities driven by a single klystron) and the low level control system, but this can be done electronically and fairly rapidly. We estimate that it will take 0.25 hour to recover and reconfigure the linac after such a failure, and this is placed in the MTTR column for the corresponding subsystems. We assume that there is no second failure, and that the failed components are replaced during the next weekly scheduled maintenance period. When the klystron fails, sometimes it will be a benign failure, such as loss of its vacuum. Other times the defective klystron must be replaced, for example if the klystron is arcing. We estimate that the benign klystron failure rate will be $50 \%$ of the total failures. Since the window replacement time is longer than a maintenance period, the window failures still result in 24 hours of down time.

Table 6. Down time allocation for the $805 \mathrm{MHz}$, Super Conducting CCL RF System.

This gives an effective MTTR for the klystrons of 2.25 hours. With these assumptions, we get a total unscheduled down time for the redundant super conducting RF system of 197.0 hours per year. The down time calculations for the redundant case in the superconducting part of the linac are shown in Table 6 above.

Comparing Table 6 with Table 4, we see that while the number of failures per year that have to be repaired stays the same, the total unexpected down time is significantly reduced. The sum of the down times, with the designed-in redundancy is 260 hours, and the availability improves to an acceptable $95.7 \%$.

\section{CONCLUSIONS}

The RF system for the SNS linac is designed to have an availability of $94.3 \%$. This model provides the basis for component sensitivity studies, and at first glance, the RF windows (with $39 \%$ of the unscheduled down time) are the weak link in the reliability chain. The next three leading causes of down time are the transmitters $(18.8 \%)$, the klystrons, $(12.2 \%)$, and the circulators $(9.8 \%)$. The remaining components each contribute less than $6.84 \%$ each to the down time. The next step in the availability study is to include the ion injector, linac cavities, the beam transport system, the accumulator ring, the target, and the balance of plant in the model and thereby arrive at the total reliability and availability estimates. It is also possible to include estimates of the temporal distributions of failures and repair times, once such estimates are made.

\section{REFERENCE}

[1] D. Rees et al.,'The RF System Design for the Spallation Neutron Source', This Conference. 